\title{
Prevalence of Pulmonary Thromboembolism in Patients Admitted to Emergency Department
}

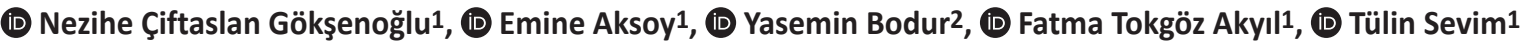 \\ 1istanbul Süreyyapaşa Chest Diseases And Thoracic Surgery Training And Research Hospital, Department of Chest Diseases, Istanbul, Turkey \\ 2 University of Health Sciences, Diyarbakır Gazi Yaşargil Health Training and Research Hospital, Department of Chest Diseases, Diyarbakır, Turkey
}

\section{Abstract}

Objective: Pulmonary thromboembolism (PTE) is caused by thrombus originating from deep leg veins and obstructing the pulmonary artery and/ or its branches. PTE is a preventable disease with high mortality and morbidity. It may relapse and is sometimes difficult to diagnose. Unnecessary diagnostic tests are applied to many patients with suspected PTE. The aim of this study was to investigate the frequency of PTE in patients presenting with a preliminary diagnosis of PTE to emergency clinic of a tertiary chest diseases hospital.

Methods: The triage forms of all patients who were admitted to the emergency clinic of tertiary chest diseases hospital within one year were examined. Demographic characteristics, risk factors for PTE, examinations and definite diagnosis data were obtained from the automation system of our hospital and evaluated retrospectively.

Results: In 2012, the number of patients admitted to the emergency department was 33,413 and 411 patients (0.12\%) were examined with preliminary diagnosis of PTE. After initial evaluation, 292 patients (71\%) were hospitalized, 117 patients (28.5\%) were called for outpatient clinic follow-up, and two patients were referred to another hospital with non-PTE diagnosis (0.5\%). After examinations at outpatient clinic or hospital admission, PTE was detected in 111 patients (27\%) and deep vein thrombosis was found in 19 patients (4.6\%). While 236 patients (57.4\%) were diagnosed as non-PTE, 6 patients (1.5\%) died before a definite diagnosis and 39 patients (9.5\%) did not attend outpatient clinic examinations. PTE was detected in 16.2\% ( $\mathrm{n}=19$ ) of the patients followed in outpatient clinic and in $31.5 \%(n=92)$ of the hospitalized patients.

Conclusion: In conclusion, the frequency of suspected PTE was $0.12 \%$ in patients admitted to the emergency department and $27 \%$ of these patients were diagnosed with definite PTE.

Keywords: Diagnosis, emergency department, pulmonary thromboembolism

\section{INTRODUCTION}

Pulmonary thromboembolism (PTE) is caused by thrombus originating from deep leg veins and obstructing the pulmonary artery and/or its branches. PTE is a preventable disease with high mortality and morbidity. It may relapse and is sometimes difficult to diagnose. The average annual incidence of venous thromboembolism (VTE) is 23-269/100.000 and it increases with age. The risk of VTE is 10 times higher after 80 years of age than at the age of $45-50$ years (1-4).
Emergency physicians and chest disease specialists often demand some tests more than necessary to exclude the diagnosis of PTE. Although D-dimer test is widely used, false positive rate is high. In addition, when the pulmonary computed tomography (CT) angiography is used more than necessary in the emergency department, it has high cost and many other risks such as radiation and contrast-induced acute kidney failure (5).

Although pulmonary CT angiography is a very effective method in the diagnosis of thromboembolic lesions located in the main and lobar pulmonary artery branches, its sensitivity in 
the diagnosis of thrombi affecting subsegmental branches is limited. The main reasons for this limitation are the performed examination, the quality of the examination and the experience of the radiologist (6).

In this study, the tests conducted in patients admitted to the emergency clinic of a tertiary chest diseases hospital with suspected PTE and the prevalence of definite PTE diagnosis among these patients were retrospectively evaluated.

\section{METHODS}

In this study, the patients who were admitted to the emergency department with suspected PTE between January-December 2012 were examined. The prevalence of PTE was investigated retrospectively.

Our hospital is a tertiary chest diseases hospital with 605 beds. The patients are referred from hospitals inside and outside Istanbul or they can be transported directly from their houses by 112 ambulance service. Patients admitted to the emergency department of our hospital are evaluated by a chest disease specialist and a resident. After the initial intervention and the necessary examinations, patients are prescribed and sent home or referred to the outpatient clinic for further examination. The patients with indication for hospitalization are hospitalized in the service or respiratory intensive care unit. If there is a suspected disease other than chest diseases, the patient is referred to the related outpatient clinic.

Complete blood count, routine biochemistry tests, ELISA D-dimer, arterial blood gas (ABG), electrocardiogram (ECG) and posteroanterior chest X-ray can be done in the emergency setting. The lower extremity venous Doppler ultrasonography (USG) can be performed at daytime outpatient clinic settings. During the study, pulmonary CT angiography and ventilationperfusion (V/P) scintigraphy tests were not performed in our hospital and patients were referred to contracted centers.

A majority of patients with suspected PTE after initial evaluation and examination are hospitalized and treated. During the hospitalization, further examination and imaging procedures are done by contacting with the contracted centers. Some patients are treated in the intensive care unit if needed. Patients whose general condition is good and who do not need hospitalization or who do not accept hospitalization are referred to the outpatient clinic, and further procedures and examinations are planned from there. If the patients do not have the possibility of being evaluated in the outpatient clinic on the same day, PTE treatment is started with low molecular weight heparin at the outpatient clinic.

In this study, triage forms of the patients who applied to our hospital between 01.01.2012-31.12.2012 were examined. The demographic characteristics of the patients, risk factors for PTE, examinations and definite diagnosis data were obtained from the triage forms and the automation system of our hospital and evaluated retrospectively. ABG and D-dimer values on admission were recorded. The values of patients with and without PTE were compared. Bilateral lower extremity venous Doppler USG was performed for the diagnosis of deep vein thrombosis, which is a risk factor for PTE. ABG and D-dimer values in patients with and without deep vein thrombosis (DVT) were compared.

\section{RESULTS}

In 2012, the number of patients admitted to the emergency department was 33.413. During this period, 411 patients (0.12\%) were examined for suspected PTE. While 50 (12\%) of these 411 patients with suspected PTE were referred from another health institution, 361 patients (88\%) presented with various complaints and were evaluated as suspected PTE by emergency physicians. Two hundred and forty-one patients (59\%) were female and 170 (41\%) were male, and the mean age was $62 \pm 18$ (17-103) years. Risk factors for PTE were detected in 241 patients (55\%). These risk factors include advanced age, major surgical intervention, long-term travel history, presence of malignancy, previous embolism, and oral contraceptive use.

As a laboratory evaluation, all patients underwent chest X-ray and oxygen saturation measurement with pulse oximetry. ABG and D-dimer values were checked in 226 patients (55\%) and 276 patients (67\%), respectively (Table 1 and Table 2). After the initial evaluation, 292 patients (71\%) were hospitalized, 117 patients (28.5\%) were called for outpatient clinic follow-up, and two patients were referred to another hospital with non-PTE diagnosis (0.5\%) (Table 3).

After examinations at outpatient clinic or hospital admission, PTE was detected in 111 patients (27\%) and deep DVT was found in 19 patients (4.6\%). While 234 (57.4\%) patients were diagnosed as non-PTE, 6 patients (1.5\%) died before a definite diagnosis and 39 patients (9.5\%) did not attend outpatient clinic examinations. Within this group, there were also patients who were planned to be examined after hospitalization and their results were also planned to be controlled in the outpatient clinic after discharge. Since these patients did not attend to outpatient clinic for showing their results, their diagnosis was not finalized. 
PTE was detected in $16.2 \%(n=19)$ of the patients followed in outpatient clinic and in $31.5 \%(n=92)$ of the hospitalized patients. Massive PTE was found in $1.8 \%(n=2)$ of 111 diagnosed patients. These patients were monitored in the intensive care unit and diagnosed by echocardiography.

The mean length of hospitalization was $9.8 \pm 4.6$ days (1-27 days). For diagnosis in hospitalized patients, 126 bilateral lower extremity venous Doppler USG (thrombus in 27.8\%), 100 CT angiography (thrombus findings in 58\%) and $39 \mathrm{~V} / \mathrm{Q}$ scintigraphy (33.3\% diagnostic for PTE) were performed.

\section{DISCUSSION}

The annual incidence of VTE is 23-269/100.000 (1) and it is known to increase with age. While the incidence of VTE was 1/10.000 in the 4th decade of life, it increases rapidly after 45 years of age and reaches 5-6/1000 around 80 years of age (7). With the new imaging methods, the number of patients examined for PTE and the rate of diagnosis increase (8). Particularly, the widespread use of CT angiography plays an important role in this increase. The effect of increase in diagnosis rates on patient prognosis is controversial. Wiener et al. (9) reported that initiation of treatment to a larger number of patients with the development of diagnostic methods did not significantly reduce mortality. In addition, pulmonary CT angiography increases the length of stay in the emergency room and increases the exposure to radiation. Besides, contrast-induced acute kidney failure can also be seen.

In our study, the prevalence of PTE was $0.12 \%$ in patients admitted to the emergency department of our hospital, and $27 \%$ of these patients were diagnosed with definite PTE. In other words, the incidence of PTE in our study was 332/10.000.
Compared to the studies performed in our country, the number of patients admitted with a preliminary diagnosis of PTE and the number of patients diagnosed with definite PTE within one year are very high in our study $(10,11)$. Since our hospital is an emergency service clinic where only respiratory diseases are evaluated, the incidence of PTE is expected to be higher. Some of our patients have been sent from other health institutions, including patients with new-onset PTE during hospitalization in the internal medicine clinics of other hospitals or after surgery. Three hundred and sixty-one patients (81\%) admitted themselves with various respiratory symptoms such as dyspnea and chest pain. This finding shows that PTE is an important diagnosis in patients admitting to the emergency clinic of tertiary chest

\begin{tabular}{|l|l|}
\hline \multicolumn{2}{|l|}{$\begin{array}{l}\text { Table 3. Distribution of diagnosis of } 411 \text { patients with } \\
\text { suspected PTE after pre-evaluation in emergency department }\end{array}$} \\
\hline & $\mathbf{n}(\%)$ \\
\hline Inpatient follow-up ( $\mathrm{n}=292)$ & $92(31.5 \%)$ \\
PTE & $19(6.5 \%)$ \\
DVT & $170(58.2 \%)$ \\
Non-PTE & $6(2)$ \\
Dead & $5(1)$ \\
Other* & \\
\hline Outpatient clinic follow-up ( $\mathrm{n}=117)$ & $19(16 \%)$ \\
PTE & 0 \\
DVT & $64(55 \%)$ \\
Non-PTE & $34(29 \%)$ \\
Other** & $2(0.5 \%)$ \\
\hline Transfer to another hospital ( $\mathrm{n}=2)$ & \\
\hline *The patient whose diagnosis is not definite because he/she did not attend \\
outpatient clinic controls after discharge. **Patients who did not attend to \\
outpatient clinic controls \\
PTE: Pulmonary thromboembolism, DVT: Deep vein thrombosis \\
\hline
\end{tabular}

\begin{tabular}{|l|l|l|l|l|l|}
\hline Table 1. Arterial blood gas values of patients with pulmonary thromboembolism & PTE $\mathbf{n}(\%)$ & DVT $\mathbf{n}(\%)$ & Non-PTE $\mathbf{n}(\%)$ & 0thers $\mathbf{n}(\%)$ & Total \\
\hline Arterial blood gas & $2(15.4 \%)$ & 0 & $10(76.9 \%)$ & $1(7.7 \%)$ \\
\hline Normal & $10(25.6 \%)$ & $2(5.1 \%)$ & $24(61.5 \%)$ & $3(7.7 \%)$ & 13 \\
\hline Hypocapnic & $6(14.6 \%)$ & $3(7.3 \%)$ & $30(73.2 \%)$ & $2(4.8 \%)$ \\
\hline Hypoxic & $45(34.1 \%)$ & $4(3 \%)$ & $72(54.5 \%)$ & $11(8.3 \%)$ \\
\hline Hypoxic hypocapnic & $63(28 \%)$ & $9(4 \%)$ & $136(60.4 \%)$ & $17(7.6 \%)$ \\
\hline Total & & & & \\
\hline PTE: Pulmonary thromboembolism, DVT: Deep vein thrombosis
\end{tabular}

\begin{tabular}{|l|l|l|l|l|l|}
\hline Table 2. D-dimer levels of patients with preliminary pulmonary thromboembolism diagnosis \\
\hline D-dimer & PTE $\mathbf{n}(\%)$ & DVT $\mathbf{n}(\%)$ & Non-PTE $\mathbf{n}(\%)$ & 0thers $\mathbf{n}(\%)$ & Total \\
\hline Normal & 0 & 0 & $19(73.1 \%)$ & $7(26.9 \%)$ & 26 \\
\hline High & $59(23.7 \%)$ & $16(6.4 \%)$ & $145(58.2 \%)$ & $29(11.6 \%)$ & 249 \\
\hline Total & $63(28 \%)$ & $16(5.8 \%)$ & $164(59.6 \%)$ & $36(13.1 \%)$ & 275 \\
\hline PTE: Pulmonary thromboembolism, DVT: Deep vein thrombosis & \\
\hline
\end{tabular}


diseases hospitals and that it should be considered in the differential diagnosis.

In our study, the data of the patients admitted to emergency room with a preliminary PTE diagnosis were evaluated and it was found that most of the patients with suspected embolism were hospitalized (71\% were hospitalized and $28.5 \%$ were called to the outpatient clinic control). According to the results, 31.5\% of the patients hospitalized with suspected PTE and $16.2 \%$ of the patients called to the outpatient clinic control were diagnosed with definite PTE. An important result was that $29 \%$ of the patients who were called to the outpatient clinic for further examination did not attend follow up. These patients were also likely to have PTE. Therefore, we think that it is important to inform the patients about the importance of the suspected disease and the importance of coming to the outpatient clinics. Difficulties in working conditions and high number of patients in emergency departments play a role in failure to do these disclosures as required.

There are several studies evaluating clinical and laboratory tests for diagnosing a disease in emergency departments, some parameters and scoring systems come to the fore. In the emergency department of our hospital, first of all, a clinical risk assessment is made by parameters such as age, symptom, physical examination findings, risk factors for VTE, ABG findings, then CT angiography, V/P scintigraphy or Doppler USG is planned regarding D-dimer level and chest radiography. However, there are deficiencies in the processing of these clinical evaluation results in triage forms as clinical risk scores. Therefore, the diagnostic value of clinical scoring systems has not been discussed in our study.

In our clinical practice, the most important parameter leading to suspected PTE after symptoms is the presence of risk factors for PTE. If there is any risk factor in a patient with chest pain and shortness of breath, PTE is immediately taken into differential diagnoses. In this study, risk factor was found in 55\% of patients with suspected PTE. The prevalence of DVT, which is an important risk factor for PTE, is 56/100.000 in all patients who applied to the emergency department in our study. In our study, the most common risk factors for DVT were immobilization and advanced age. Other risk factors were history of malignancy, surgery and DVT.

Another parameter used in clinical evaluation is ABG findings. Although $A B G$ findings are not diagnostic alone, it may lead to suspicion of PTE. In our study, 63 out of 225 patients who were evaluated with ABG were diagnosed with PTE. Only 2 patients had normal ABG values. While the most common blood gas measurement in PTE was hypoxic, hypocapnic blood gas values, it was found that these values could also be seen in patients diagnosed with non-PTE. The main consideration in the diagnosis of PTE is that most of the patients with normal blood gas have been diagnosed with a non-PTE.

D-dimer is a test used with more negative predictive value in the diagnosis of PTE. It can be positive in many cases other than PTE. In practice, it is recommended to switch to diagnostic methods such as CT angiography without D-dimer in patients with high clinical scoring. In our study, no PTE was detected in any of the patients with normal/low D-dimer level. The level of D-dimer was not normal in any of the patients diagnosed with PTE, but it was higher than normal in patients diagnosed with DVT. In contrast, 58\% of 249 patients with high D-dimer had PTE and non-DVT diagnoses.

\section{Study Limitations}

In our study, CT angiography was performed in 100 patients with suspected PTE and thrombus was found in 58\% of the patients. In other patients, PTE was diagnosed or excluded by other methods. At that time, the availability of CT angiography in emergency conditions in our hospital may have limited the use of this examination.

\section{CONCLUSION}

In this study, the prevalence of PTE and clinical approach in the emergency clinic of a tertiary chest diseases hospital were evaluated. The symptoms and signs of PTE can be confused with many respiratory diseases. PTE is an important disease with high rates of morbidity and mortality. The clinical suspicion of emergency physicians and a wide differential diagnosis approach are vital for rapid diagnosis and treatment.

\section{Ethics}

Ethics Committee Approval: Retrospective study.

Informed Consent: Retrospective study.

Peer-review: Externally peer-reviewed.

\section{Authorship Contributions}

Surgical and Medical Practices: N.Ç.G., Concept: T.S., Design: T.S., Data Collection or Processing: Y.B., Analysis or Interpretation: E.A., Literature Search: Y.B., Writing: F.T.A.

Conflict of Interest: No conflict of interest was declared by the authors.

Financial Disclosure: The authors declared that this study received no financial support. 


\section{REFERENCES}

1. Arseven O, Ekim N, Müsellim N.Türk Toraks Derneği Pulmoner Tromboembolizm Tanı ve Tedavi Uzlaşı Raporu 2015.

2. Rosendaal FR. Risk factors for venous thrombotic disease. Thromb Haemost 1999;82:610-9.

3. Silverstein MD, Heit JA, Mohr DN. Trends in the incidence of deep vein thrombosis and pulmonary embolism; A 25-year population-based study. Arch Intern Med 1998;158:585-93

4. Tsai AW, Cushman M, Rosamond WD, et al. Cardiovascular risk factors and venous thromboembolism incidence: the longitudinal investigation of thromboembolism etiology. Arch Intern Med 2002;162:1182-9.

5. Aydoğdu M, Sınanoglu N, Dogan N, Oguzulgen K.Acil Servislerde Pulmoner Tromboemboli Ön Tanısı ile Gereksiz Tetkik Yapılması Wells Skoru ve Pulmoner Emboli Ekartasyon Kriterleri ile Önlenebilir mi?. Tuberk Toraks 2014;62:12-21.

6. Arıyürek M, Akpınar M, Türkbey B.Pulmoner tromboemboli (PTE) tanısında görüntüleme yöntemleri ve son gelișlmeler. Hacettepe Tıp Dergisi 2009;40:151-6.
7. Șen N, Ermiş H, Altınkaya N. Genç ve yaşlı pulmoner embolili olgularımız: Klinik özellikler, laboratuvar ve instrumental bulgular ve yaş gruplarına göre farklılıklar. Tur Toraks Der 2010;11:160-6.

8. Duru S, Ergün R, Dilli A, Kaplan T, Kaplan B, Ardıç S. Pulmoner embolide klinik, laboratuvar ve bilgisayarlı tomografi pulmoner anjiyografi sonuçları: 205 hastanın retrospektif değerlendirmesi. Anadolu Kardiyol Derg 2012;12:142-9.

9. Wiener RS, Schwartz LM, Woloshin S. Time trends in pulmonary embolism in the United States: evidence of overdiagnosis. Arch Intern Med 2011;171:8317.

10. Yılmaz S, Topçu F, Selimoğlu Șen H, Abakay Ö, Yılmaz Z. Pulmone emboli tanısında Wells klinik skorlaması ile yüksek D-dimer seviyesinin kombinasyonu. Journal of Clinical and Experimental Investigations 2014; 5:557-62.

11. Gülcü A, Akkoçlu A, Yılmaz E et al. Pulmoner emboli tanısında klinik olasılıkların bilgisayarlı tomografi pulmoner anjiyografi bulguları ile karșılaștırılması. Tüberküloz ve Toraks Dergisi 2007;55:174-81. 